SPP Communiqués are brief articles that deal with a singular public policy issue and are intended to provide the reader with a focused, concise critical analysis of a specific policy issue.

Copyright @ 2013 by The School of Public Policy.

All rights reserved. No part of this publication may be reproduced in any manner whatsoever without written permission except in the case of brief passages quoted in critical articles and reviews.

The University of Calgary is home to scholars in 16 faculties (offering more than 80 academic programs) and 36 Research Institutes and Centres including The School of Public Policy. Under the direction of Jack Mintz, Palmer Chair in Public Policy, and supported by more than 100 academics and researchers, the work of The School of Public Policy and its students contributes to a more meaningful and informed public debate on fiscal, social, energy, environmental and international issues to improve Canada's and Alberta's economic and social performance.

\section{GRASPING AT STRAWS: COMMENTS ON THE ALBERTA PIPELINE SAFETY REVIEW}

\author{
Jennifer Winter ${ }^{\dagger}$
}

\section{SUMMARY}

The release last month of the Alberta Pipeline Safety Review was meant to be a symbol of the province's renewed commitment to environmental responsibility as it aims for new export markets. The report's authors, Group 10 Engineering, submitted 17 recommendations covering public safety and pipeline incidents, pipeline integrity management and pipeline safety near bodies of water - and many of them run the gamut from the obvious to the unhelpful to the contradictory. That the energy regulator ought to be staffed to do its job should go without saying; in fact, staffing levels were never identified as an issue. The recommendation that record retention and transfer requirements be defined for mergers and acquisitions, sales and takeovers is moot. There is no reason a purchasing party would not want all relevant documents, and no real way to enforce transparency if the seller opts to withhold information. Harmonizing regulations between provinces could reduce companies' cost of doing business, but could also prove challenging if different jurisdictions use performance-based regulations - which is what the Review recommended Alberta consider. This very brief paper pries apart the Review's flaws and recommends that the province go back to the drawing board. Safety is a serious issue; a genuine statistical review linking pipeline characteristics to failures and risk-mitigation activities would be a better alternative by far.

\footnotetext{
$\dagger$ Thanks to Michal Moore, Andrew Wilkins and two anonymous referees for their valuable comments.
} 
Pipeline safety is an issue throughout the world, reflecting an apparent increase in the frequency of accidents, recognition of system age and vulnerabilities, and increased media attention. In Alberta, Group 10 Engineering was engaged as an independent third party by the Energy Resources Conservation Board (now the Alberta Energy Regulator) to review pipeline safety in Alberta. Their report is available at http://www.energy.alberta.ca/Org/pdfs/PSRfinalReportNoApp.pdf. The purpose of the report was to assess current regulatory requirements and industry best practices related to public safety and pipeline incidents, pipeline integrity management, and the safety of pipelines near bodies of water. The Group 10 Engineering report was released to the public on August 23, 2013. The focus of the report was comparing Alberta's regulatory framework to the frameworks of other jurisdictions. The report outlined 17 recommendations for improving pipeline safety.

The purpose of this communique is to review and comment on the practicality and feasibility of 13 of the 17 recommendations. The recommendations are reviewed in the order they appear in the Alberta Pipeline Safety Review. ${ }^{l}$

In general, the recommendations are superficial and of little practical use for improving pipeline safety in Alberta. In some cases, unintended consequences from the recommendations may compromise pipeline safety. This is a serious policy concern, as time is of the essence and scarce public funds must be directed and spent judiciously in order to maintain public health and safety. A review of the key flaws includes:

\section{PUBLIC SAFETY AND RESPONSE TO PIPELINE INCIDENTS}

Recommendation \#1: Regulators and licensees could jointly develop a stakeholder education/awareness program on the consequences of right-of-way encroachment and how to react in the event of an emergency.

The definition of stakeholder matters in energy system operations and oversight. There are many potential stakeholders, each with a different role and responsibility, and any recommendation should be clear on who the stakeholders are. Pipeline and facility licensees are required to have emergency response plans (vetted by the regulator), and so, additional education likely has little value to them.

If one stakeholder considered is the general public, ${ }^{2}$ then there may be some value in additional education. A major consequence of right-of-way encroachment is pipeline rupture, which the majority of individuals undoubtedly appreciate. However, the public is not likely to understand or appreciate the level of risk associated with encroachment. There is currently a substantial amount of promotion of the Alberta One Call system, which focuses on prevention, so it is not clear if additional educational programming is required.

I refrain from commenting on the recommendations regarding the safety of pipelines near water, as they are more technical in nature and are direct recommendations for changing Alberta Energy Regulator (AER) regulations.

2 The Alberta Energy Regulator does not have a definition of what a stakeholder is, but the Alberta government identified stakeholder groups as: environmental non-governmental organizations, landowners and groups representing landowners, municipalities, the oil, gas and oil sands industries, and the coal industry. See various documents from the Regulatory Enhancement Task Force. 
Recommendation \#2: The Call Before You Dig (Alberta 1 Call) membership requirement is legislated as compulsory in Alberta for pipeline licensees; but this is not the case nationally. Consideration should be given to instituting this as a Canada wide program. Not only would this benefit other jurisdictions where it is not a requirement, but it would also ensure that new Albertans are consistently aware of these requirements.

The Alberta One Call system is aimed at the prevention of pipeline damage by educating homeowners and contractors, as well as by providing information on the location of buried utilities prior to ground disturbances. Membership makes it mandatory to provide sufficient information to anyone undertaking a ground disturbance. As the program already exists in Alberta, making a call-before-you-dig program mandatory nationally would have a minimal effect on pipeline safety in Alberta.

Recommendation \#3: ERCB staff should consider increased participation in stakeholder hosted emergency response exercises, as these present an opportunity to share knowledge as well as provide an opportunity to the regulatory staff to informally review ERP [emergency response plan] documents and processes.

The Alberta Energy Regulator's Directive 071 outlines emergency preparedness and response requirements for industry. There is also an overview of the AER's emergency response plan, which includes suggestions for industry to improve their emergency response. As well, licensees must submit their emergency response plans for approval by the AER, and will need to address any outstanding concerns before approval occurs. ${ }^{3}$ Additional input by regulatory staff simply does not add to or improve public safety and may encourage a false complacency. Moreover, informal input brings the risk of miscommunication, as well as compromising safety.

\section{PIPELINE INTEGRITY MANAGEMENT}

Recommendation \#1: Institute the risk ranking of all pipelines based on standardized methodology to be developed by Canadian regulators and stakeholders.

While an inventory of pipelines is a useful tool for the AER, it is not clear a risk ranking of pipelines provides a benefit, unless it supports a broad enforceable program of remediation. A more useful tool is a predefined threshold for pipeline safety that should be stringently regulated and enforced. If all pipelines are above the safety threshold, they are, by definition, not risky, or at least satisfy the principle of keeping risk as low as reasonably practicable. ${ }^{4}$ If pipelines are below the threshold, then the regulator should address these deficiencies through enforcement actions.

\footnotetext{
3 See Appendix 2: ERP Approval Application in "Directive 071: Emergency Preparedness and Response Requirements for the Petroleum Industry," http://www.aer.ca/rules-and-regulations/directives/directive-071 (viewed August 28, 2013).

4 Though there is an argument for different risk tolerances depending on location and the product transported via pipeline.
} 
Facilities regulated by the AER are already audited, and audits are prioritized by operator (licensee/contractor) history, sensitivity of the location, and the inherent risk of the project or operation. ${ }^{5}$ It is not clear how a risk ranking would enhance the AER's (or any other regulator's) ability to regulate pipeline safety. Requiring this ranking would certainly demand additional resources and may create confusion among other stakeholders and the public at large.

Recommendation \#2: Integrity Management Programs for all companies under the ERCBs jurisdiction should be audited on a routine basis for compliance with respect to adequacy, implementation and effectiveness. Given the number of licensees in Alberta, this is potentially a near impossible task for the ERCB to achieve on its own. Consideration should be given to accepting self or third party audits from licensees; complemented by random and risk assessed requirements for ERCB led audits (which could vary in intensity or focus as required).

This recommendation is suggesting, without saying it explicitly, that there are not enough audits, but the AER cannot feasibly perform all the audits. The challenge is to strike a balance between self-enforcement of standards by pipeline companies and ensuring standards are met via audits by the regulator. The issue of industry self-governance can be contentious, especially in industries where public health and safety is an issue and public trust may be strained.

For the operators or licensees of pipelines, there are major financial penalties from ruptures: the cost of cleanup, the cost of shutting a pipeline down, and whatever enforcement penalties are applied. Even non-compliance carries financial penalties. There is also the associated loss of public trust and a tarnished corporate image. These costs create the financial incentive to maintain pipeline safety, combined with standards prescribed by the regulator. That said, there may be short-term gains to firms from compromising safety.

Third-party and government audits should be indistinguishable from each other, as they are both via an independent third party. The monies spent on third-party audits could just as easily be used to increase staff at the regulator (regardless of who was paying for the audit), but so long as independence is maintained, third-party audits would be sufficient for evidence of compliance. The benefits of self-auditing should already be captured in mandatory activities to ensure compliance. Firms should already be self-auditing in order to ensure their integrity management programs meet the requisite standards set by the regulator. To ensure compliance or to verify the results of self-audits, the regulator would still need to conduct its own audits. As a result, implementing the recommendation would likely not improve pipeline safety.

\footnotetext{
5 "Inspections and Audits," Alberta Energy Regulator, http://www.aer.ca/compliance-and-enforcement/inspections-andaudits, (viewed August 27, 2013).
} 
Recommendation \#3: Set minimum requirements for comprehensive inspection and testing programs for pipelines to establish the current condition of pipelines in assessed high-risk areas as identified in recommendation 1 above.

Minimum safety standards should be sufficient to ensure pipeline safety throughout the system, including high-risk areas. As stated in Directive 066, "compliance in meeting or exceeding regulations and standards is the responsibility of the energy industry. The ERCB expects all industry participants to understand its requirements and have an infrastructure in place to ensure compliance." ${ }^{\circ}$ The regulator outlines requirements for maintaining pipeline safety. Beyond that, it is the responsibility of operators and licensees to engage in behaviour to meet the minimum requirements. Unless the minimum standards are inadequate, additional requirements will provide no additional benefit.

Recommendation \#4: Work with appropriate education or industry institutions to develop certification programs for individuals (operators, construction and integrity inspectors and supervisors) in the areas of pipeline safety, including construction, operation, inspection and integrity management.

A lack of training, either in regulator employees or industry employees, was not identified as an issue by the report. Moreover, both energy regulators and energy facility licensees and operators have every incentive to hire and retain adequately trained individuals in these areas. For regulators, the public relies on them to adequately inspect energy facilities. The loss of public trust following a rupture of a just-inspected pipeline would be substantial. Presumably, current employees of the regulator and the operators and licensees are adequately trained.

Developing certification programs creates two issues. The first is that adequate inspection will be dependent on having certified employees within the regulator and within the company. This will create an artificial supply constraint on the number of inspectors, and in a worst-case scenario, lead to fewer inspections. This recommendation could actually decrease pipeline safety. The second issue is that certificate programs add on a layer of needless requirements for adequate training - it is in the best interests of both firms and regulators to have the best possible staff.

6 Alberta Energy Regulator, "Directive 066: Requirements and Procedures for Pipelines" 
Recommendation \#5: Where appropriate the ERCB should consider using performance-based regulation for those licensees whose performance warrants such an approach (this approach is used by the pressure equipment regulator in Alberta and is the trend among major regulators such as PHMSA and in the EU). This process should be evolutionary with compliance audits providing the necessary confidence for the transition to a performance-based system.

Regulators can direct the behaviour of those they govern in two basic ways. Prescriptive regulation involves the regulator prescribing the actions required for the regulated entity to improve their performance. Performance-based (or goal-based) regulation states the desired goal or level of performance, and allows the targets of regulation to decide how to achieve that level. ${ }^{7}$ The report provides no evidence in support of performance-based regulation improving safety compared to prescriptive regulation. Without evidence, it is impossible to validate the benefit of changing the regulatory structure, which would certainly carry considerable costs.

Additionally, the way the report authors compared Alberta to other jurisdictions was an assessment and comparison of regulatory provisions beyond those prescribed by the CSA Z662 standards. Using this methodology, the more additional regulations a jurisdiction has, the better it ranks in the report. Moving from prescriptive regulation to performance-based regulation would decrease the number of regulations faced by firms in Alberta. If the authors believe that performance-based recommendation is a substitute for prescriptive regulation, then their chosen methodology to compare jurisdictions is incorrect.

Recommendation \#6: ERCB should be staffed appropriately to manage and enforce regulations (whether prescriptive or performance based) to ensure pipeline safety and integrity.

It goes without saying that any regulator should be staffed appropriately to fulfill their mandate. As neither the level of staffing at the ERCB, nor the ability of the ERCB to adequately "manage and enforce regulations," were identified as issues by the G10 report, this recommendation is a) obvious and b) not helpful.

Recommendation \#7: ERCB should work collaboratively with stakeholders to set clear goals and objectives to focus and manage the reduction of pipeline failures to a level as low as reasonably practicable (ALARP).

The Alberta Energy Regulator provides the enabling Act, along with Regulations, Directives and Bulletins on its website. Together, these set out the minimum safety standards for operating pipelines in Alberta. The goal for firms operating pipelines is to meet or exceed these standards. As none of the standards were identified by the report as inadequate, this recommendation does little more than state the obvious.

7 For an overview of advantages and disadvantages of the two types of regulation, see Coglianese, Cary; Nash, Jennifer; Olmstead, Todd, (2003) "Performance-Based Regulation: Prospects and Limitations in Health, Safety, and Environmental Protection," Administrative Law Review 55 (1) p. 705 
Recommendation \#8: Record retention and transfer requirements, specifically during takeovers, mergers, acquisitions and sales, should be clearly defined in the regulation.

There is no reason a purchasing party would not want all relevant documentation for the asset they are purchasing. Usually, sale contracts include a schedule of assets and associated documentation. If the seller withheld information required to maintain a minimum safety standard, they would certainly be considered partly responsible, if not liable. Moreover, if companies for some reason do not transfer records, the only knowledge of the records would lie with the seller. The buyer would have no way of knowing these records exist, or retrieving them. Without evidence of incomplete records due to a change in ownership leading to a pipeline rupture, there is no reason to create a regulation that is, at best, ineffective and non-enforceable.

Recommendation \#9: The ERCB should work with other regulators to harmonize regulatory requirements and support a consistent regulatory basis for stakeholders (for example the recently stated key performance indicators required by the National Energy Board could be considered for adoption by the ERCB). The use of a standard such as CSA Z662 is a valuable tool in promoting harmonization.

Harmonizing regulatory requirements reduces the cost of doing business across jurisdictions, making it a laudable policy goal. However, if the regulatory requirements across jurisdictions are sufficient for a minimum safety standard - and there is no evidence otherwise - harmonization is not a pipeline safety issue. Moreover, harmonization is not necessarily viable if different jurisdictions are using performancebased regulation. This recommendation is inconsistent with the above recommendation to move to performance-based regulation.

Recommendation \#10: Third party encroachment and pipeline interference is still a major concern to licensees. Additional education of industries and the public as to the risks and regulatory requirements of working near pipelines could be promoted. Some licensees stated the setback requirements are inadequate for class 4 areas (where there is presently municipal development, or a high future potential for municipal development).

The Alberta Energy Regulator's report Pipeline Performance in Alberta, evaluates pipeline performance between 1990 and 2012. ${ }^{8}$ In the report, "damage by others" is the fourth most frequent cause of failures, accounting for 4.5 per cent of failures between 1990 and 2012. However, when breaking down incidents by type of pipeline, damage by others is much more frequent: 19.7 per cent for crude oil pipelines, 9.6 per cent for sour gas pipelines and 15.2 per cent for natural gas pipelines. That said, corrosion (internal and external) is still the predominant cause of pipeline incidents. While prevention of damage by others is certainly important, more work is required in prevention by pipeline licensees, which is under the purview of the AER. This speaks to the need for improved inspections and technology. Influencing the behaviour of individuals and contractors is beyond the scope and ability of the AER.

8 Alberta Energy Regulator Report 2013-B: "Pipeline Performance in Alberta, 1990-2012," http://www.aer.ca/documents/reports/R2013-B.pdf (viewed August 27, 2013). 


\section{Conclusions and Recommendations}

The 13 recommendations analyzed here unfortunately do little to address pipeline safety in Alberta. While not all are flawed, many are weak and provide little guidance for the regulator as to what steps should be taken to improve pipeline safety and public trust. The province should strongly consider commissioning another report with broader scope. While the Group 10 report did assess the regulatory requirements in Alberta and compare these requirements to other jurisdictions, a comparison of regulations does not adequately address the issue of pipeline safety. What is required is a statistical review analyzing pipeline characteristics and relating these to failures, inspections and other risk-mitigation activities. Facts about the relationship between pipeline characteristics (age, material) and the risk of failure are what are needed to improve pipeline safety and restore public trust. 


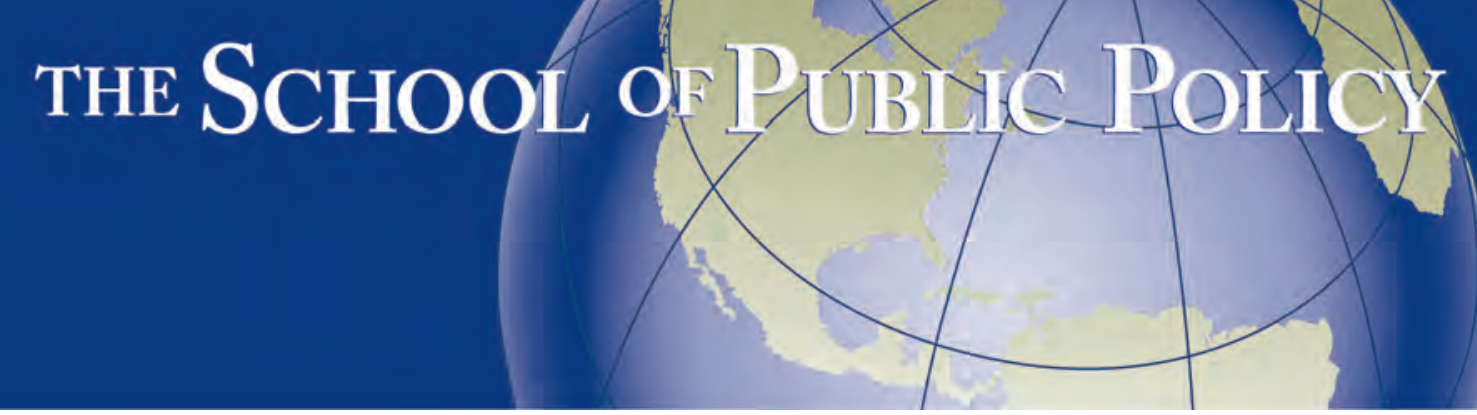

\section{About the Author}

Jennifer Winter, (PhD) is a Research Associate in the Energy and Environmental Policy at The School of Public Policy. Her research is focused on the effects of government regulation on the development of natural resources. Jennifer has authored several research papers for The School, including two on Canadian energy literacy. Prior to joining The School, she worked at Human Resources and Skills Development Canada in Ottawa, analysing Canadian labour markets. 